\title{
Distribution and diversity of Wolbachia in different populations of the wheat aphid Sitobion miscanthi (Hemiptera: Aphididae) in China
}

\author{
Zhe WANG, Zuo-Rui SHEN*, Yue SONG, Hong-Yue LIU and Zheng-XI LI
}

IPMist Lab, Department of Entomology, College of Agronomy and Biotechnology, China Agricultural University, 100193 Beijing, China, e-mails: wzhe1226@gmail.com; songyue409@gmail.com; caulhy@163.com; zxl@cau.edu.cn

Key words. Cytoplasmic symbiont, wheat aphid, Wolbachia, Sitobion miscanthi, distribution, diversity, China, 16s rDNA gene

\begin{abstract}
Wolbachia is a widely distributed intracellular symbiont in the reproductive tissues of arthropods. The wheat aphid Sitobion miscanthi (Takahashi) is an important agricultural pest worldwide. Wolbachia was detected in different populations of $S$. miscanthi in China using 16s rDNA and wsp-specific primers. Of eighteen populations eleven were infected with Wolbachia. Several strains of Wolbachia infected these $S$. miscanthi populations. Of the eleven infected populations, four were infected with only one Wolbachia strain and seven with double infections. This is the most systematic survey of the distribution of Wolbachia in the wheat aphid.
\end{abstract}

\section{INTRODUCTION}

Wolbachia is a common cytoplasmic symbiont that resides in the reproductive tissues of many arthropods (Juchault et al., 1994; Johanowicz \& Hoy, 1995; Sironi et al., 1995; Werren et al., 1995; Rowley et al., 2004). Recent surveys have found Wolbachia in over $20 \%$ of insect species, including each of the major insect orders (Lo et al., 2007).

The wheat aphid, Sitobion miscanthi (Takahashi) (Hemiptera: Aphididae), is a major and widespread pest of cereal crops in China. It inflicts economic damage directly by sap-sucking and indirectly by transmitting the barley yellow dwarf and millet red leaf persistent luteoviruses (Blackman \& Eastop, 2000). Because of the considerable reproductive potential, life cycle and behavioural plasticity of this wheat aphid, further characterization of the Wolbachia infection of this aphid is needed in order to understand the effect of this symbiont on aphid reproduction and evolution. West et al. (1998) used 16s rDNA and ftsZ genes to survey four species of aphid: Aphis jacobaeae, Capitophorus carduinus, Microlophium carnosum and Sitobium fragariae, but did not find Wolbachia in any of these species. This was the first report on Wolbachia in aphids. Two years later, Jeyaprakash \& Hoy (2000) tested sixty-three arthropod species distributed in sixteen orders using the long PCR method with wsp gene, which encodes a surface protein of Wolbachia. Among these arthropods Wolbachia was detected in two species of aphids: Toxoptera citricida (Kirkaldy) and Aphis craccivora (Koch), with A-Wolbachia identified in T. citricida (Kirkaldy). This A-Wolbachia sequence is the same as the strain wSus-A1 (GB No. AF217713). Tsuchida et al. (2002) conducted an investigation of the distribution of some endosymbiotic bacteria in Japanese populations of the pea aphid, Acyrthosiphon pisum. In spite of the prevalence of secondary endosymbiotic bacteria, Wolbachia was not detected. Nirgianaki et al. (2003) analysed twenty-four DNA samples of aphids provided by Paul Baumann (University of California, Davis, USA). These aphids included Acyrthosiphon pisum, Aphis craccivora, Diuraphis noxia, Myzus persicae, Rhopalosiphum padi, Uroleucon spp. etc. None of these species was infected with Wolbachia. Then Kittayapong et al. (2003) investigated tropical rice-field community insects in Thailand. Forty-nine of 209 rice-field insect species were infected with Wolbachia. Of these insects most were Homoptera (54.2\%), but the aphid Hysteroneura setariae (Thomas) was not infected with Wolbachia. In 2004, Gómez-Valero et al. amplified and sequenced the 16s rDNA and wsp genes of Wolbachia in the aphid Cinara cedri. The phylogenetic analysis based on the wsp gene indicated that this kind of Wolbachia belonged to group Con of supergroup B. In addition, their results indicate that Wolbachia coexists with two other endosymbionts: Buchnera aphidicola (the primary endosymbiont in aphids) and $\mathrm{S}$ symbiont (a secondary symbiont). This is the first record of Wolbachia in an aphid observed using electron microscopy.

In this paper, we characterized the pattern of Wolbachia infection in natural populations of wheat aphid in China by identifying the strains and determining their relationships with the supergroups of Wolbachia already described. Eighteen natural populations of wheat aphid, $S$. miscanthi, were screened for infection using Wolbachiaspecific $16 \mathrm{~s}$ rDNA and wsp genes.

\section{MATERIAL AND METHODS}

\section{Aphid samples}

All the aphid samples used in this study were collected from eighteen areas of China where wheat is grown (Fig. 1). In order to avoid collecting offspring of the same mother, only one aphid was collected from each location, which were ten meters apart.

\footnotetext{
* Corresponding author; e-mail: ipmist@163.com
} 
These aphids were kept in $100 \%$ ethanol at $-20^{\circ} \mathrm{C}$ until DNA extraction.

\section{DNA extraction}

DNA was extracted according to the protocols described by Vavre et al. (1999) with slight modifications. An aphid was washed in double distilled water and then ground in $200 \mu \mathrm{l}$ extraction buffer $\left(100 \mathrm{mmolL}^{-1}\right.$ Tris- $\mathrm{HCl}, \mathrm{PH} 7,1.4 \mathrm{molL}^{-1} \mathrm{NaCl}$, $20 \mathrm{mmolL}^{-1}$ EDTA, $2 \% \mathrm{CTAB}$ ) and incubated at $65^{\circ} \mathrm{C}$ for $1 \mathrm{~h}$. Then $1 \mu \mathrm{l}$ RNase was added and the solution incubated at $37^{\circ} \mathrm{C}$ for 1 h. $500 \mu$ chloroform-isoamylic alcohol $(24: 1)$ was added before centrifugation for $15 \mathrm{~min}$ at $13,000 \mathrm{rpm}$. The supernatant was collected and gently mixed with double volumes of $100 \%$ ethanol and tenth of volume of Na-acetate $\left(3 \mathrm{~mol} \mathrm{~L}^{-1}, \mathrm{PH} 5.2\right)$. After precipitation over night at $-20^{\circ} \mathrm{C}$ and centrifuged for 20 min at $13,000 \mathrm{rpm}$ and the precipitate of DNA collected. The precipitate was washed with $70 \%$ ethanol and air dried. Finally $20 \mu 11 \times$ TE buffer was added to dissolve the DNA sample, which was then stored at $-20^{\circ} \mathrm{C}$ until tested.

\section{Wolbachia detection}

Three diagnostic PCRs were performed to amplify a fragment of the 28s rDNA gene of the aphid and of the $16 \mathrm{~s}$ rDNA and wsp genes of Wolbachia.

The 28s rDNA gene is universally present in eukaryotes and highly conserved. The primers based on the $28 \mathrm{~s}$ rDNA gene were used to check for the quality of DNA extraction. The primers were forward (5'TAC CGT GAG GGA AAG TTG AAA) and reverse (5'AGA CTC CTT GGT CCG TGT TT). PCR cycling conditions were a 2 min pre-dwell at $94^{\circ} \mathrm{C}$ followed by 38 cycles of $30 \mathrm{~s}$ at $94^{\circ} \mathrm{C}, 50 \mathrm{~s}$ at $58^{\circ} \mathrm{C}, 90 \mathrm{~s}$ at $72^{\circ} \mathrm{C}$ and a post-dwell period of $10 \mathrm{~min}$ at $72^{\circ} \mathrm{C}$. Samples negative for $28 \mathrm{~s}$ rDNA gene were discarded. The $16 \mathrm{~s}$ rDNA primers, which were forward (5'CAT ACC TAT TCG AAG GGA TAG) and reverse (5'AGC TTC GAG TGA AAC CAA TTA), were used to screen for Wolbachia infection. PCR cycling conditions were a $2 \mathrm{~min}$ pre-dwell at $94^{\circ} \mathrm{C}$ followed by 38 cycles of $30 \mathrm{~s}$ at $94^{\circ} \mathrm{C}, 45 \mathrm{~s}$ at $55^{\circ} \mathrm{C}, 90 \mathrm{~s}$ at $72^{\circ} \mathrm{C}$ and a post-dwell period of 10 min at $72^{\circ} \mathrm{C}$. The aphid samples that were positive were reamplified using $16 \mathrm{~s}$ rDNA and $w s p$ primers $(81 \mathrm{~F} / 522 \mathrm{R}$; $136 \mathrm{~F} / 691 \mathrm{R})$ using the PCR conditions described above Zhou et al. (1998).

PCRs were performed in $25 \mu 1$ reaction volumes: $2.5 \mu 110 \times$ PCR buffer, $2.5 \mu 125 \mathrm{mM} \mathrm{MgCl}_{2}, 2 \mu 1 \mathrm{dNTPs}$ (10 mM each), $15 \mu \mathrm{ldd} \mathrm{H}_{2} \mathrm{O}, 1.5 \mu \mathrm{l} 10 \mu \mathrm{M}$ forward and reverse primers and 1 unit Taq DNA polymerase. DNA extracts of Wolbachiainfected Trichogramma evanesceus were used as positive controls. Negative controls containing only double-distilled water were also included to check for contamination.

\section{Cloning and sequencing}

PCR products of the 16S rDNA and wsp gene segment were purified using a DNA Fragment Purification kit (Sangon). Purified PCR products were cloned in the plasmid vector pMD19-T (TaKaRa) and transformed into Escherichia coli DH5 $\alpha$ competent cells. The nucleotide sequences of selected clones were sequenced on an ABI automated sequencer (ABI Prism 377, USA). Both strands of plasmids were sequenced using universal primers (M13+, M13-) with forward and reverse reads. At least three independent clones were sequenced from each Wolbachia strain in order to identify polymerase errors.

\section{Alignments and genetic analyses}

Similar sequences to these of the $16 \mathrm{~S}$ rDNA and wsp genes obtained from the wheat aphid were searched for in GenBank, using BLAST. The 16S rDNA sequences were aligned with the representative dataset of sequences from all supergroups

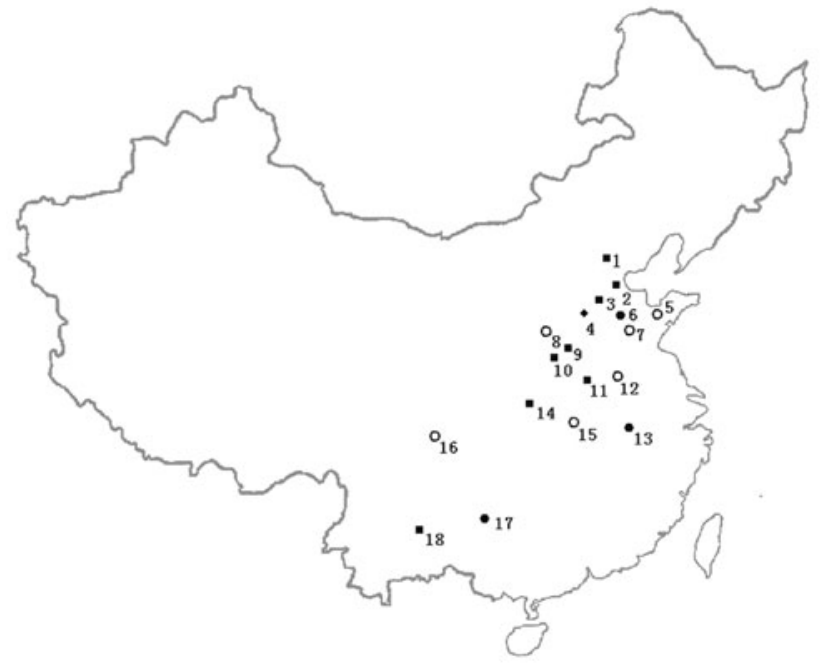

Fig. 1. Map of the sampling locations of S. miscanthi (Takahashi) in China. (Note: The islands of South China Sea that belong to China are not included in this map.) 1 - Beijing, $2-$ Cangzhou, 3 - Hengshui, 4 - Xingtai, 5 - Weifang, 6 - Jinan, 7 - Taian, 8 - Lingfen, 9 - Xinxiang, 10 - Louyang, 11 - Luohe, 12 - Mencheng, 13 - Anqing, 14 - Shiyan, 15 - Xiaogan, 16 Chengdu, 17 - Duyun, 18 - Kunming. $\$$-population infected with A-Wolbachia; $\bullet$ - population infected with B-Wolbachia; - population infected with A and B-Wolbachia; O - population not infected with Wolbachia.

described except supergroup G. Sequences of $w s p$ were aligned with sequences from $33 \mathrm{~A}$ - and B-Wolbachia strains downloaded from GenBank (Table 2) followed by manual adjustments based on the amino acid translation of the different genes. Phylogenetic analyses were conducted with neighbour-joining (NJ) and maximum parsimony (MP) methods using MEGA 4.0 (Tamura et al., 2007). For maximum parsimony analysis, the close-neighbour-interchange (CNI) search method was used with the initial tree using random addition trees (10 repetitions). Alignment gaps were excluded and bootstrap analysis carried out with 1,000 replications. For NJ analysis, distances were calculated using the Kimura 2-Parameter model and bootstrap tests performed with 1,000 replications. The phylogenetic tree was constructed using the NJ method.

\section{Recombination analyses of $w s p$ gene}

Analysis of recombination was done using the part of the $w s p$ gene. Four $w s p$ sequences, $w$ MisBJA1, $w$ MisBJA1, $w$ MisBJA2, $w$ MisBJA3 and $w$ MisBJB, from infected wheat aphids were aligned with 33 published sequences (Table 2) for recombination analyse. Automated RDP tool implemented in the program RDP2 was used. Default parameters were used and the highest acceptable $P$ value cutoff was 0.01 .

\section{RESULTS}

\section{Prevalence of Wolbachia in S. miscanthi}

This extensive targeted survey for Wolbachia infection in S. miscanthi using PCR amplification of the $16 \mathrm{~S}$ rDNA gene revealed two different $16 \mathrm{~S}$ rDNA genes in this wheat aphid. The phylogenetic analysis indicated that the two $16 \mathrm{~S}$ rDNA sequences belonged to the separate supergroups A and B (Fig. 2).

Of the eighteen geographical populations of S. miscanthi sampled in China, eleven (61\%) were infected with 

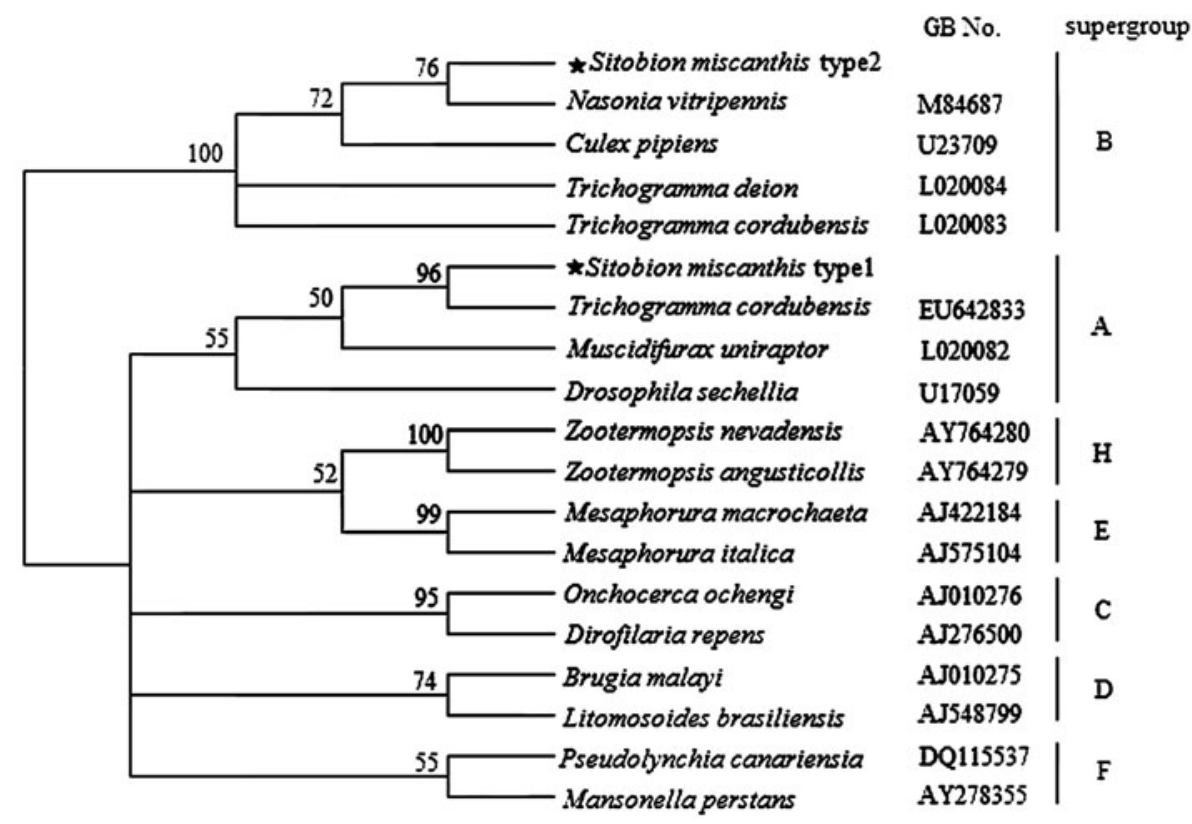

Fig. 2. Phylogenetic tree of Wolbachia based on 16S rDNA sequences constructed using NJ method in MEGA. S. miscanthi indicated by " $\star$ ".

Wolbachia, with all the individuals in the population infected. The same phenomenon is also found in whiteflies and leafhoppers (Nirgianak et al., 2003). The reason for this is not clear. Four populations (HBXT, SDJN, AHAQ and GZDY) were infected with only one strain of Wolbachia. There were double infections of all individuals in seven populations: BJ, HBCZ, HBHS, HNXX, HNLY, HNLH and YNKM, and seven populations (SDWF, SDTA, SXLF, AHMC, HBSY, HBXG and SCCD) were not infected by any type of Wolbachia (Table 1).

\section{Phylogeny and recombination of wsp gene}

The twenty wsp sequences obtained belong to group Kue, Eva, Mis and Pip, respectively, of which Kue, Eva and Mis belong to supergroup A, Pip to supergroup B (Fig. 3). Group Kue, Eva and Pip are described but Mis is a new group. Intragenic recombination within the wsp gene was shown using the Siscan and RDP methods in RDP2. One recombination fragment was detected in $w$ MisBJA3. The major and minor parents were identified as $w$ Mors and $w$ Ha. The size of the recombination frag-

TABLE 1. Distribution of Wolbachia in different populations of S. miscanthi in China based on 16S rDNA gene.

\begin{tabular}{|c|c|c|c|c|c|c|}
\hline \multicolumn{2}{|c|}{ Location } & \multirow{2}{*}{ Code } & \multirow{2}{*}{ Longitude } & \multirow{2}{*}{ Latitude } & \multirow{2}{*}{ Total no. tested } & \multirow{2}{*}{$\begin{array}{c}\text { Type of Wolbachia } \\
\text { infection }\end{array}$} \\
\hline Province & City & & & & & \\
\hline Beijing & & $\mathrm{BJ}$ & E116.46 & N39.92 & 30 & A, B \\
\hline \multirow{3}{*}{ Heibei } & Cangzhou & HBCZ & E116.83 & N38.33 & 30 & $\mathrm{~A}, \mathrm{~B}$ \\
\hline & Hengshui & HBHS & E115.72 & N37.72 & 30 & $\mathrm{~A}, \mathrm{~B}$ \\
\hline & Xingtai & HBXT & E114.48 & N37.05 & 24 & $\mathrm{~A}$ \\
\hline \multirow{3}{*}{ Shandong } & Weifang & SDWF & E119.1 & N36.62 & 16 & None \\
\hline & Jinan & SDJN & E117.0 & N36.65 & 12 & B \\
\hline & Taian & SDTA & E117.95 & $\mathrm{N} 37.50$ & 16 & None \\
\hline Shanxi & Linfen & SXLF & E111.5 & $\mathrm{N} 36.08$ & 16 & None \\
\hline \multirow{3}{*}{ Henan } & Xinxiang & HNXX & E113.85 & N35.31 & 30 & $\mathrm{~A}, \mathrm{~B}$ \\
\hline & Luoyang & HNLY & E112.44 & N34.70 & 30 & $\mathrm{~A}, \mathrm{~B}$ \\
\hline & Luohe & HNLH & E114.02 & $\mathrm{N} 33.56$ & 24 & $\mathrm{~A}, \mathrm{~B}$ \\
\hline \multirow{2}{*}{ Anhui } & Mengcheng & AHMC & E116.55 & $\mathrm{N} 33.25$ & 20 & None \\
\hline & Anqing & AHAQ & E117.03 & $\mathrm{N} 30.52$ & 12 & $\mathrm{~B}$ \\
\hline \multirow{2}{*}{ Hubei } & Shiyan & HBSY & E110.79 & N32.65 & 16 & None \\
\hline & Xiaogan & HBXG & E113.91 & N31.92 & 22 & None \\
\hline Sichuan & Chengdu & SCCD & E104.06 & N30.67 & 12 & None \\
\hline Guizhou & Duyun & GZDY & E107.53 & $\mathrm{N} 26.72$ & 12 & $\mathrm{~B}$ \\
\hline Yunnan & Kunming & YNKM & E102.73 & $\mathrm{N} 25.04$ & 30 & $\mathrm{~A}, \mathrm{~B}$ \\
\hline
\end{tabular}




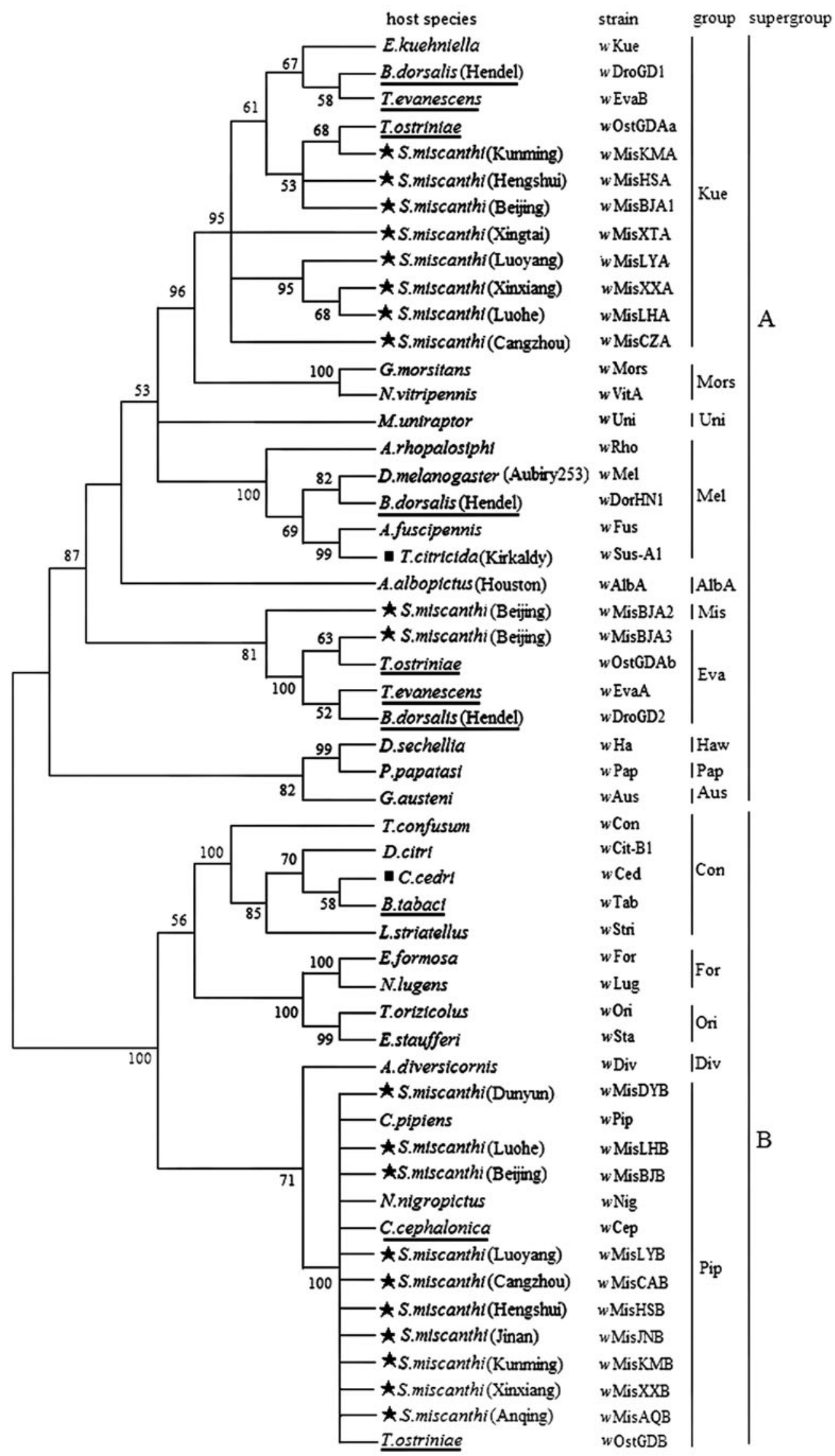

Fig. 3. Phylogenetic tree of Wolbachia based on wsp gene constructed using NJ method. S. miscanthi indicated by “ $\star$ ”, other aphids by " $\mathbf{\square}$ ", other insects from China are underlined. 
TABLE 2. Host, associated Wolbachia wsp gene sequences and GenBank accession numbers.

\begin{tabular}{|c|c|c|c|c|}
\hline Supergroup & Group & Wolbachia host species & Wolbachia strain & GenBank accession \\
\hline \multirow{29}{*}{ A } & \multirow{5}{*}{ Mel } & Drosophila melanogaster Meigan (Aubiry253) & $w \mathrm{Mel}$ & AF020063 \\
\hline & & Amitus fuscipennis MacGown \& Nebeker & $w$ Fus & AF071909 \\
\hline & & Toxoptera citricida (Kirkaldy) & wSus-A1 & AF217713 \\
\hline & & Bactrocera dorsalis (Hendel) & $w$ DorHN1 & DQ834379 \\
\hline & & Aphidius rhopalosiphi De Stefani Perez & $w$ Rho & AJ631306 \\
\hline & AlbA & Aedes albopictus (Skuse) (Houston) & $w \mathrm{AlbA}$ & AF020058 \\
\hline & \multirow{2}{*}{ Mors } & Glossina morsitans Westwood & $w$ Mors & AF020079 \\
\hline & & Nasonia vitripennis Walker & $w$ VitA & AF020081 \\
\hline & \multirow{12}{*}{ Kue } & Ephestia kuehniella (Zeller) & $w$ Kue & AF071911 \\
\hline & & Bactrocera dorsalis (Hendel) & $w$ DroGD1 & DQ288282 \\
\hline & & Trichogramma ostriniae (Pang \& Chen) & wOstGDAa & EU157103 \\
\hline & & Trichogramma evanescens Westwood & $w$ EvaB & AY390280 \\
\hline & & Sitobion miscanthi (Takahashi) (Beijing) & $w$ MisBJA1 & EU302498 \\
\hline & & Sitobion miscanthi (Takahashi) (CangZhou) & $w \mathrm{MisCZA}$ & EU302501 \\
\hline & & Sitobion miscanthi (Takahashi) (HengShui) & $w$ MisHSA & EU302502 \\
\hline & & Sitobion miscanthi (Takahashi) (XingTai) & $w$ MisXTA & EU302503 \\
\hline & & Sitobion miscanthi (Takahashi) (XinXiang) & $w$ MisXXA & EU302504 \\
\hline & & Sitobion miscanthi (Takahashi) (LuoYang) & $w$ MisLYA & EU302505 \\
\hline & & Sitobion miscanthi (Takahashi) (LuoHe) & $w$ MisLHA & EU302506 \\
\hline & & Sitobion miscanthi (Takahashi) (KunMing) & $w$ MisKMA & EU302507 \\
\hline & Uni & Muscidifurax uniraptor Kogun \& Legner & $w$ Uni & AF020071 \\
\hline & Haw & Drosophila sechellia (Tsacas \& Bächli) & $w \mathrm{Ha}$ & AF020073 \\
\hline & Pap & Phlebotomus papatasi (Scopoli) & $w$ Pap & AF020082 \\
\hline & Aus & Glossina austeni Newst & $w$ Aus & AF020077 \\
\hline & \multirow{4}{*}{ Eva } & Trichogramma evanescens Westwood & $w$ EvaA & AY390279 \\
\hline & & Bactrocera dorsalis (Hendel) & $w$ DroGD2 & DQ288284 \\
\hline & & Trichogramma ostriniae (Pang \& Chen) & $w O s t G D A b$ & EU157104 \\
\hline & & Sitobion miscanthi (Takahashi) (Beijing) & $w$ MisBJA3 & EU302500 \\
\hline & Mis & Sitobion miscanthi (Takahashi) (Beijing) & $w$ MisBJA2 & EU302499 \\
\hline \multirow{24}{*}{ B } & \multirow{5}{*}{ Con } & Tribolium confusum Jacquelin du Val & $w$ Con & AF020083 \\
\hline & & Laodelphax striatellus Fallen & $w$ Stri & AF020080 \\
\hline & & Cinara cedri Mimeur & $w C e d$ & AY620433 \\
\hline & & Diaphorina citri Kuwayama & $w$ Cit-B1 & AF217721 \\
\hline & & Bemisia tabaci (Gennadius) & $w \mathrm{Tab}$ & AY567791 \\
\hline & Div & Apoanagyrus diversicornis (Howard) & $w$ Div & AF071916 \\
\hline & \multirow[t]{2}{*}{ For } & Encarsia formosa Gahan & $w$ For & AF071918 \\
\hline & & Nilaparvata lugens (Stål) & $w$ Lug & AF481181 \\
\hline & \multirow{2}{*}{ Ori } & Tagosodes orizicolus (Muir) & $w$ Ori & AF020085 \\
\hline & & Eretmocerus staufferi Rose \& Zolnerowick & $w$ Sta & AF071919 \\
\hline & \multirow{14}{*}{ Pip } & Culex pipiens Pallens & $w$ Pip & AF020061 \\
\hline & & Nephotettix nigropictus (Stål) & $w$ Nig & AF481177 \\
\hline & & Corcyra cephalonica (Stainton) & $w$ Cep & AY634679 \\
\hline & & Trichogramma ostriniae (Pang \& Chen) & $w$ OstGDB & EU157105 \\
\hline & & Sitobion miscanthi (Takahashi) (BeiJing) & $w$ MisBJB & EU302508 \\
\hline & & Sitobion miscanthi (Takahashi) (CangZhou) & $w \mathrm{MisCZB}$ & EU302509 \\
\hline & & Sitobion miscanthi (Takahashi) (JiNan) & $w$ MisJNB & EU302510 \\
\hline & & Sitobion miscanthi (Takahashi) (XinXiang) & $w$ MisXXB & EU302511 \\
\hline & & Sitobion miscanthi (Takahashi) (HengShui) & $w$ MisHSB & EU302512 \\
\hline & & Sitobion miscanthi (Takahashi) (LuoYang) & $w$ MisLYB & EU302513 \\
\hline & & Sitobion miscanthi (Takahashi) (LuoHe) & $w$ MisLHB & EU302514 \\
\hline & & Sitobion miscanthi (Takahashi) (AnQing) & $w$ MisAQB & EU302515 \\
\hline & & Sitobion miscanthi (Takahashi) (DuYun) & $w$ MisDYB & EU302516 \\
\hline & & Sitobion miscanthi (Takahashi) (KunMing) & $w$ MisKMB & EU302517 \\
\hline
\end{tabular}


ment is 43 bp (beginning breakpoint 421/ending breakpoint 464).

\section{DISCUSSION}

\section{Distribution of Wolbachia in S. miscanthi}

This survey of Wolbachia infections in the wheat aphid, $S$. miscanthi, in the main wheat growing areas of China detected Wolbachia in eleven of eighteen populations. Several kinds of Wolbachia infected the $S$. miscanthi populations. Of the eighteen populations examined eleven were infected, four with only one and seven with two Wolbachia strains. Double infections (at least two Wolbachia strains found in one host individual) are only recorded in some homopteran species, such as whitefly (Nirgianaki et al., 2003) and the zig-zag leafhopper (Kittayapong et al., 2003). This is the first report of a double infection in aphids.

The nature of the Wolbachia infections in the different populations differed. The reason for this is unknown, but several factors might have contributed. Migration in wheat aphids is universal in China, and may have affected the distribution of Wolbachia. The direction of migration of $S$. miscanthi in China is uncertain, so a large-scale investigation of the distribution of Wolbachia in this wheat aphid is needed.

The A-Wolbachia is rarely detected in Hemiptera but the $w$ Sus-A1 strain belonging to group $\mathrm{Mel}$ is recorded from Toxoptera citricida (Kirkaldy) (Jeyaprakash \& Hoy, 2000). However, in Chinese populations of Trichogramma and fruit flies, A-Wolbachia strains are common (Fig. 3). Most of A-Wolbachia strains detected in Chinese insect populations belong to group Kue or Eva. The $w$ DroHN1 [Bactrocera dorsalis (Hendel)] strain belongs to group $\mathrm{Mel}$ along with the wSus-A1 strain. A greater diversity of B-Wolbachia are recorded for Hemiptera (Fig. 3).

The Wolbachia recorded in $S$. miscanthi are very similar to those in other insects, such as trichogramma (Trichogramma ostriniae, Trichogramma evanescens), fruit fly [Bactrocera dorsalis (Hendel)], drosophila [Drosophila simulans (mauritiana)], mosquito (Culex pipiens), leafhopper (Nephotettix nigropictus) and rice moth (Corcyra cephalonica) (Fig. 3). These insects have no direct relationship to $S$. miscanthi, and Wolbachia is not recorded from plants, however, these insects should be linked with the complex food chain, so the most likely route is horizontal transmission. Another hypothesis is that Wolbachia was present in a distant ancestor of $S$. miscanthi and that some populations may have lost it. While this may certainly be the case for the B-Wolbachia, the A-Wolbachia appears in different groups in the phylogenetic tree indicating at least some degree of horizontal transfer.

\section{Origins and evolution of Wolbachia in S. miscanthi}

In recent years, several studies have revealed that high rates of recombination have occurred in the $w s p$ gene (Baldo et al., 2005a, b; Roy \& Harry, 2007; Verne et al., 2007), so using this gene for phylogenetic reconstruction could be misleading. Moreover, a Multilocus Sequence Typing (MLST) scheme exists for genotyping Wolbachia (Baldo et al., 2006; Baldo \& Werren, 2007). MLST is an effective means of detecting diversity among strains within a single host, as well as for identifying closely related strains found in different hosts. In this study, the recombination test performed on wsp sequences of $\mathrm{Wol}$ bachia infecting $S$. miscanthi revealed slight intragenic recombination. However, the sequences of the wsp gene used in the analysis of recombination consisted of only part of the whole wsp gene sequence. Analysis using the whole wsp gene would provide more information about recombination. As recently reported, the complete genome of $w \mathrm{Mel}$ of A-supergroup encodes the necessary machinery for recombination and has experienced both extensive intragenomic homologous recombination and introduction of foreign DNA (Wu et al., 2004). The implications of recombination are clearly of great interest. It may provide a potential motor for evolutionary change and the acquisition of new mechanisms by bacteria. Intracellular symbiosis in aphids is common. The coexistence of Wolbachia with other symbionts in aphids (GómezValero et al., 2004) is recorded. So the patterns of recombination in Wolbachia genomes could clarify important aspects of the evolution of this host-symbiont system (Baldo et al., 2005a).

The prevalence and distribution of the Wolbachia in the wheat aphid S. miscanthi suggest that the effect of Wolbachia on aphid populations merits further study.

\section{REFERENCES}

BALdo L. \& WerRen J.H. 2007: Revisiting Wolbachia supergroup typing based on WSP: spurious lineages and discordance with MLST. Curr. Microbiol. 55: 81-87.

Baldo L., Bordenstein S., Wernegreen J.J. \& Werren J.H. 2005a: Widespread recombination throughout Wolbachia genomes. Mol. Biol. Evol. 23: 437-449.

Baldo L., Lo N. \& Werren J.H. 2005b: Mosaic nature of the Wolbachia surface protein. J. Bacteriol. 187: 5406-5418.

Baldo L., Dunning Hotopp J.C., Jolley K.A., Bordenstein S.R., Biber S.A., Choudhury R.R., Hayashi C., Maiden M.C.J., Tettelin H. \& Werren J.H. 2006: Multilocus sequence typing system for the endosymbiont Wolbachia pipientis. Appl. Environ. Microbiol. 72: 7098-7110.

Blackman R.L. \& Eastop V.F. 2000: Aphid on the World's Crops: An Identification and Information Guide. 2nd ed. John Wiley \& Sons, Chichester, 345 pp.

Gómez-Valero L., Soriano-Navarro M., Pérez-Brocal V., Heddi A., Moya A., García-Verdugo J.M. \& Latorre A. 2004: Coexistence of Wolbachia with Buchnera aphidicola and a secondary symbionts in the aphid Cinara cedri. J. Bacteriol. 86: 6626-6633.

JEYAPRAKASH A. \& Hoy M.A. 2000: Long PCR improves Wolbachia DNA amplification: wsp sequence found in $76 \%$ of sixty-three arthropod species. Insect Mol. Biol. 9: 393-405.

JoHANOwicz D.L. \& Hoy M.A. 1995: Molecular evidence for A-Wolbachia endocytobiont in the predatory mite Metaseiulus occidentalis. J. Cel. Biochem. (A) 21: 198.

Juchault P., Frelon M., Bouchon D. \& Rigaud T. 1994: New evidence for feminizing bacteria in terrestrial isopods: evolutionary implications. C.R. Acad. Sci. Paris (Life Sci.) 317: 225-230. 
Kittayapong P., Jamnongluk W., Thipaksorn A., Milne J.R. \& SINDHUSAKE C. 2003: Wolbachia infection complexity among insects in the tropical rice-field community. Mol. Ecol. 12: 1049-1060.

Lo N., Paraskevopoulos C., Bourtzis K., O’Neill S.L., Werren J.H., Bordenstein S.R. \& BANDI C. 2007: Taxonomic status of the intracellular bacterium Wolbachia pipientis. Int. J. Syst. Evol. Microbiol. 57: 654-657.

Nirgianaki A., Banks G.K., Frohlich D.R., Veneti Z., Braig H.R., Miller T.A., Bedford I.D., Markham P.G., Savakis C. \& Bourtzis K. 2003: Wolbachia infections of the whitefly Bemisia tabaci. Curr. Microbiol. 47: 93-101.

Rowley S.M., Raven R.J. \& McGraw E.A. 2004: Wolbachia pipientis in Australian spiders. Curr. Microbiol. 49: 208-214.

ROY V. \& HARRY M. 2007: Diversity of Wolbachia isolated from the Cubitermes sp. affinis subarquatus complex of species (Termitidae), revealed by multigene phylogenies. FEMS Microbiol. Lett. 274: 102-111.

Sironi M., Bandi C., Sacchi L., Di Sacco B., Damiani G. \& GENCHI C. 1995: Molecular evidence for a close relative of the arthropod endosymbiont Wolbachia in a filarial worm. Mol. Biochem. Parasitol. 74: 223-227.

Tamura K., Dudley J., Nei M. \& Kumar S. 2007: MEGA4: Molecular Evolutionary Genetics Analysis (MEGA) software version 4.0. Mol. Biol. Evol. 24: 1596-1599.

Tsuchida T., Koga R., Shibao H., Matsumoto T. \& Fukatsu T. 2002: Diversity and geographic distribution of secondary endosymbiotic bacteria in natural populations of the pea aphid, Acyrthosiphon pisum. Mol. Ecol. 11: 2123-2135.

Vavre F., Girin C. \& Bouletreau M. 1999: Phylogenetic status of a fecundity enhancing Wolbachia that does not induce thelytoky in Trichogramma. Insect Mol. Biol. 8: 67-72.

Verne S., Johnson M., Bouchon D. \& Grandjean F. 2007: Evidence for recombination between feminizing Wolbachia in the isopod genus Armadillidium. Gene 397: 58-66.

Werren J.H., Guo L. \& Windsor D.W. 1995: Distribution of Wolbachia in neotropical arthropods. Proc. R. Soc. Lond (B) 262: 147-204.

West S.A., CoOK J.M., Werren J.H. \& Godfray C.J. 1998: Wolbachia in two insect host-parasitoid communities. Mol. Ecol. 7: 1457-1465.

Wu M., Sun L.V., Vamathevan J., Riegler M., Deboy R., Brownlie J.C., McGraw E.A., Martin W., Esser C., Ahmadinejad N., Wiegand C., Madupu R., Beanan M.J., Brinkad L.M., Daugherty S.C., Durkin A.S., Kolonay J.F., Nelson W.C., Mohamoud Y., Lee P., Berry K., Young M.B., Utterback T., Weidman J., Nierman W.C., Paulsen I.T., Nelson K.E., Tettelin H., O’Neill S.L. \& Eisen J.A. 2004: Phylogenomics of the reproductive parasite Wolbachia pipientis $w \mathrm{Mel}$ : A streamlined genome overrun by mobile genetic elements. PLoS Biol. 2: 327-341.

Zhou W.G., Rousset F. \& O’Neill S. 1998: Phylogeny and PCR-based classification of Wolbachia strains using wsp gene sequences. Proc. R. Soc. Lond (B) 265: 509-515.

Received January 29, 2008; revised and accepted September 11, 2008 